\title{
HEARING ASSESSMENT IN CHRONIC RENAL FAILURE PATIENTS UNDERGOING HEMODIALYSIS
}

Arjun Singh Doshad ${ }^{1}$, Vaibhav Kuchhal ${ }^{2}$

\section{HOW TO CITE THIS ARTICLE:}

Arjun Singh Doshad, Vaibhav Kuchhal. "Hearing Assessment in Chronic Renal Failure Patients Undergoing Hemodialysis". Journal of Evolution of Medical and Dental Sciences 2014; Vol. 3, Issue 04, January 27; Page: 1034-1042, DOI: $10.14260 /$ jemds/2014/1942

ABSTRACT: The auditory sensitivity of 63 patient of chronic renal failure on hemodialysis was assessed in order to know the effect of dialysis on hearing threshold. All selected patient were non diabetic with normal tympanic membrane and with no history of ototoxic drug and any hereditary hearing problems. Pure tone audiometry was done before and after dialysis and all cases were followed for 3 month. A high incidence of high frequency sensorineural hearing loss was obtained which could not be attributed to age, noise exposure and ottotoxicity. An association between high frequency sensorineural hearing loss and hemodialysis is thus suggested.

KEYWORDS: Hemodialysis; Pure tone audiometry; High frequency sensorineural hearing loss; Duration of disease; Chronic renal failure

INTRODUCTION: Many similarities anatomical, physiological, pharmacological and pathological exist between nephron and stria vascularis of the cochlea and hearing loss has been reported in patient with renal failure ${ }^{1-3}$. Although the gross anatomy of kidney and cochlea differ greatly, there are many similarities at the ultrastructural level; both contain epithelial structure in close contact with their vascular supply. Basement membrane is found closely apposed to capillary endothelium in both Bowman's capsule and proximal renal tubule of the kidney and also around the capillaries of stria vascularis.

In both, epithelial cells show feature known to be associated with active transport of fluid and electrolyte mainly microvilli containing numerous mitocondria. Both organs are involved in body fluid homeostasis and therefore have epithelium containing a sodium potassium ion pump using ATPase. Carbonic anhydrase is also present in both stria and nephron ${ }^{1}$.

Various pharmacological agent act both on inner ear and kidney and aminoglycoside antibiotics can be both nephrotoxic and ototoxic. Sensorineural hearing loss (SNHL) has been reported in Chronic Renal Failure (CRF) with prevalence of 20-40\%4. Etiopathogenetic mechanisms reported include osmotic alteration resulting in loss of hair cells, collapse of endolymphatic space, edema and atrophy of specialized auditory cells and in some cases complication of hemodialysis have been hypothesised ${ }^{5-7}$. The role of hemodialysis in causation of SHNL is controversial; some authors have reported a depression in hearing threshold after hemodialysis while others are of opinion that there was no relation between the two.7-9

MATERIAL AND METHODS: Sixty three CRF patients were recruited for Pure Tone Audiometry (PTA) at admission and after three sessions of hemodialysis. The pure tone audiometry was done in the sound - proof (acoustic) booth in the ENT clinic. The hearing acuity was measured in $\mathrm{dB}$ at the frequencies $500-8000 \mathrm{~Hz}$. The average for the four frequencies $500 \mathrm{~Hz}, 1000 \mathrm{~Hz}, 2000 \mathrm{~Hz}$ and $4000 \mathrm{~Hz}$ 
were recorded. The duration of illness, dosage of diuretic and blood pressure were also noted. The mean hearing acuity of pre- and post - hemodialysis were determined.

From October 2011 to October 2012, a prospective study was performed on 63 patients attending Sushila Tiwari Hospital; all of them were diagnosed as having acquired Chronic Kidney Disease (CKD). All Patients were kept on regular hemodialysis programs.

The age of patients ranged from 25 to 75 years. Patients who had one or more of the following were excluded from the study because these may cause SND:

1. Local otological disease.

2. Previous otological trauma or surgery.

3. Family history of hearing loss.

4. Definite exposure to ototoxic drugs by careful drug history.

5. Habitual exposure to hazardous noise such as exposure to explosions, those who work in electric generation machines.

The inclusion criteria were consecutive CRF patients who were non diabetic with normal ear and no previous history of ear surgery.

After being examined clinically, they were evaluated by audiometry, and the analysis was made of the bone conduction thresholds. Patients were divided into three age groups in order to make a precise comparison between their bone conduction thresholds and the corresponding normal audiograms.

Thus, the age groups were as follows:

Group A: 25-40 years.

Group B: 41-55years.

Group C: $56-75$ years.

The duration of CKDs was also taken into consideration and the relation between the duration of the disease and the degree of hearing loss was detected. The average bone conduction thresholds were, on the other hand, measured before and after hemodialysis on monthly bases. Blood was analyzed for creatinine, urea, glucose, sodium, potassium, calcium and cholesterol. All patients on maintenance hemodialysis twice weekly for 4-6 hours duration.

\section{OBSERVATION AND RESULTS:}

\begin{tabular}{|c|c|c|c|}
\hline Duration of disease & Number of patients & Hearing loss & $\%$ \\
\hline 0- 6 month & 45 & 16 & 33.33 \\
\hline $6-12$ month & 9 & 5 & 55.55 \\
\hline 12-18 month & 3 & 2 & 66.66 \\
\hline$>18$ month & 6 & 5 & 83.33 \\
\hline Total & 63 & 28 & 44.44 \\
\hline \multicolumn{3}{|c}{ TABLE 1}
\end{tabular}

Hearing status with duration of disease

The incidence of sensorineural hearing loss was found to increase with increasing duration of the disease. 


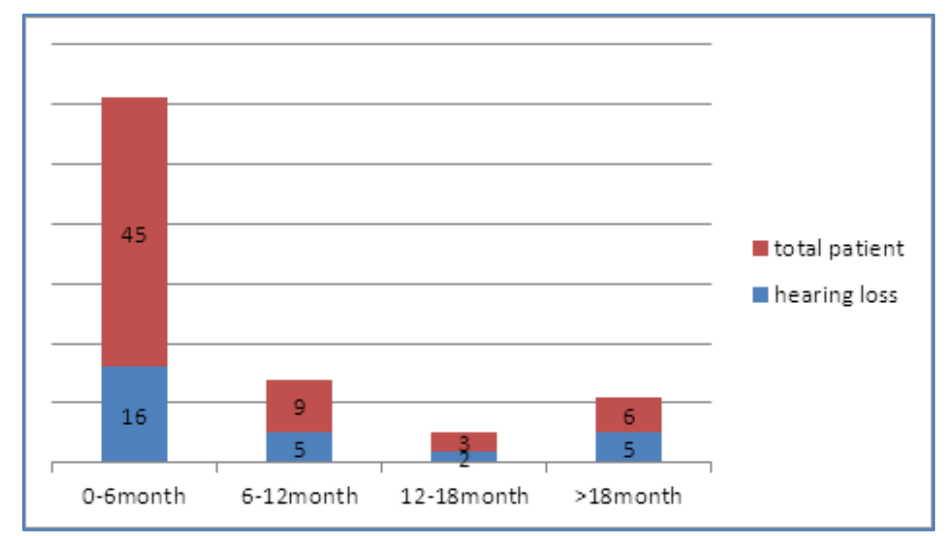

\begin{tabular}{|c|c|c|c|}
\hline Session of dialysis & Patients & Hearing loss & percentage \\
\hline $0-50$ & 56 & 29 & 51.7 \\
\hline $50-75$ & 5 & 4 & 80 \\
\hline$>100$ & 2 & 2 & 100 \\
\hline \multicolumn{4}{|c|}{ TABLE 2} \\
\hline
\end{tabular}

Relation of session of dialysis with hearing loss after three month Chi-square $=53.01367$, Significant

Total number of dialysis after three month of follow up has been found significantly affecting the hearing status of patients.

\begin{tabular}{|c|c|c|c|c|c|}
\hline Frequency & Mild & Moderate & Severe & Total & $\%$ \\
\hline High & 12 & 7 & 1 & 20 & 71.42 \\
\hline Mid & 4 & 1 & 0 & 5 & 17.85 \\
\hline Low & 2 & 1 & 0 & 3 & 10 \\
\hline \multicolumn{5}{|c|}{ TABLE 3 }
\end{tabular}

Hearing status of patients at the time of presentation

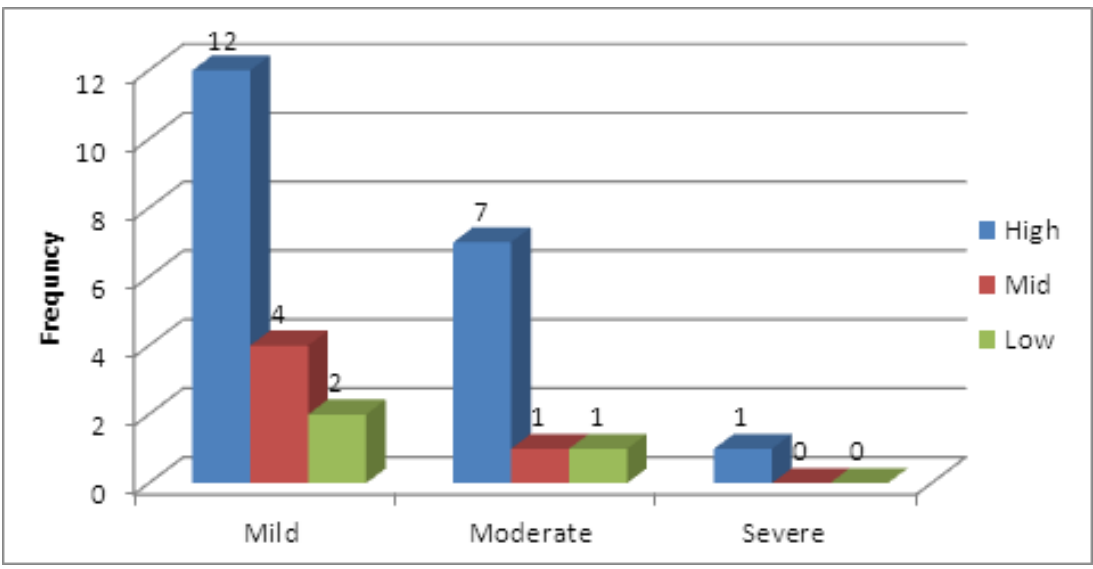

High frequency sensorineural hearing loss: 20 Mid frequency sensorineural hearing loss: 5 Low frequency sensorineural hearing loss: 3 
The sensorineural hearing loss was found to affect the high frequency more than the mid and low frequency. The sensorineural hearing loss was more of mild degree in $64.28 \%$ of patients and moderate degree in $32.14 \%$ and severe degree in $3.57 \%$ of patients undergoing hemodialysis. Total hearing loss was $44.44 \%$.

\begin{tabular}{|l|c|c|c|c|c|}
\hline Severity & High frequency & Mid frequency & Low frequency & Total & $\%$ \\
\hline Mild & 8 & 2 & 2 & 12 & 34.28 \\
\hline Moderate & 15 & 3 & 1 & 19 & 54.28 \\
\hline Severe & 4 & 0 & 0 & 4 & 11.49 \\
\hline Total & 27 & 5 & 3 & 35 & 55.55 \\
\hline percentage & 77.14 & 14.28 & 8.5 & & \\
\hline \multicolumn{7}{|c}{ TABLE 4 }
\end{tabular}

Hearing status after three month of duration:

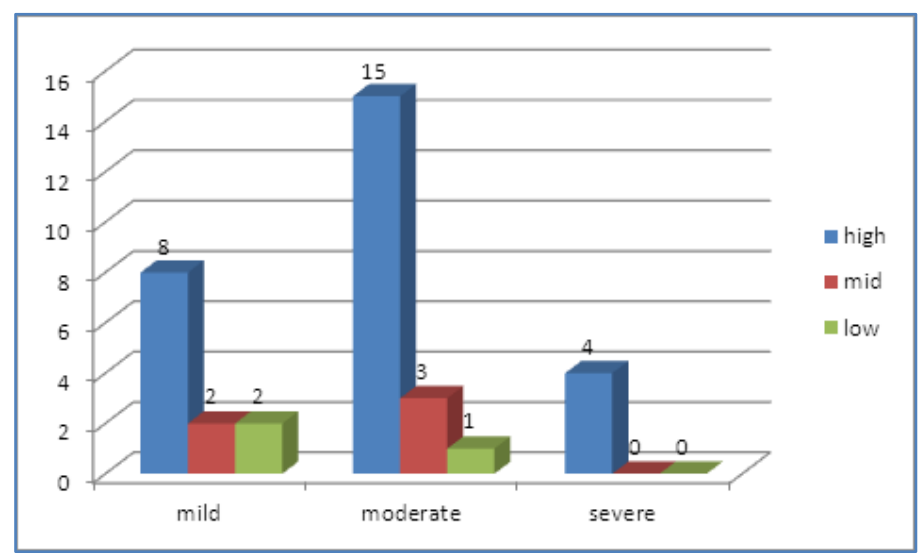

Mild sensorineural hearing loss: 12 Severe sensorineural hearing loss: 4

Moderate sensorineural hearing loss: 19

High frequency hearing loss: 27 mid frequency hearing loss: 5

Low frequency hearing loss: 3

There is increment in hearing loss of moderate and severe degree in patients of chronic renal failure undergoing hemodialysis.

Total hearing loss was 55.55\%.

\begin{tabular}{|l|c|c|c|c|c|c|}
\hline & $\mathbf{2 5 0 h z}$ & $\mathbf{5 0 0 h z}$ & $\mathbf{1 0 0 0 h z}$ & $\mathbf{2 0 0 0 h z}$ & $\mathbf{4 0 0 0 h z}$ & $\mathbf{8 0 0 0 h z}$ \\
\hline 0-6 month & 13 & 19 & 24 & 30 & 34 & 34 \\
\hline 6-12 month & 24 & 24 & 30 & 34 & 36 & 42 \\
\hline 12-18 month & 26 & 30 & 32 & 34 & 40 & 48 \\
\hline >18 month & 28 & 32 & 34 & 43 & 46 & 60 \\
\hline
\end{tabular}

TABLE 5: average bone conduction thresholds according to the duration of renal failure 


\section{ORIGINAL ARTICLE}

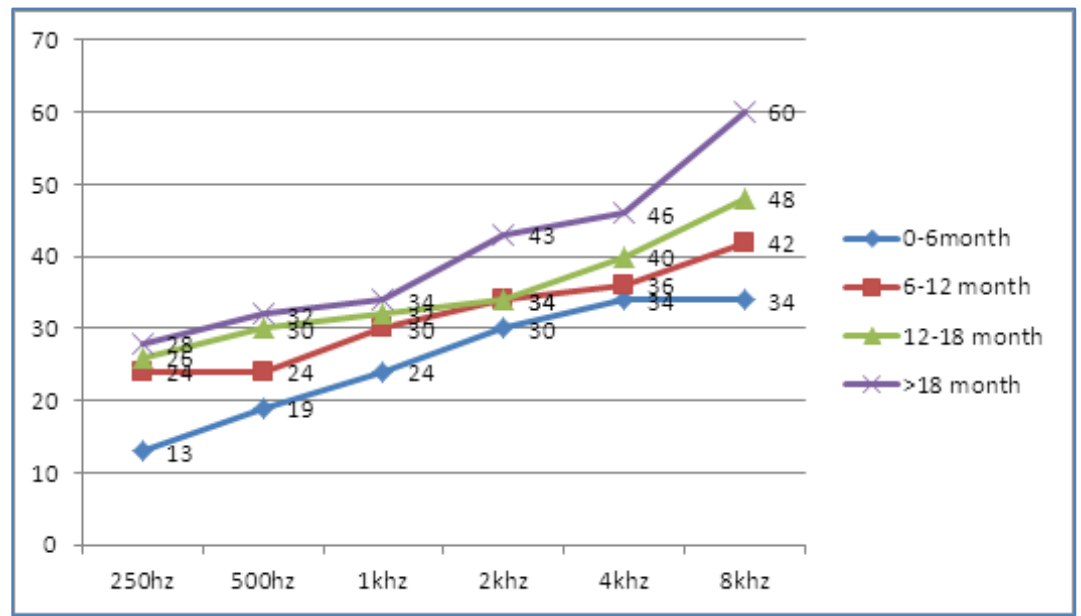

The average bone conduction thresholds were estimated according to the duration of renal failure.

The hearing loss is noted to increase with the duration of disease and with the sessions of dialysis mostly in higher frequency.

\begin{tabular}{|c|c|c|c|c|c|c|c|c|c|c|c|c|c|}
\hline \multicolumn{14}{|c|}{ PTA11 ' PTAB Crosstabulation } \\
\hline & & \multicolumn{11}{|c|}{ PTA3 } & \multirow[b]{2}{*}{ Total } \\
\hline & & mild HFSNHL & modht & SNHL & $\begin{array}{l}\text { severet } \\
\text { SNHL }\end{array}$ & & mild chl & mod chl & milly SNAHL & milf mf SNHL & $\bmod n f$ SNHL & $n$ & \\
\hline \multirow[t]{9}{*}{ PTA1 } & mildSHSWH. & 5 & & 6 & & 1 & 0 & 0 & 0 & 0 & 0 & 0 & 12 \\
\hline & modttSNHL & 0 & & 6 & & 2 & 0 & 0 & 0 & 0 & 0 & 0 & 8 \\
\hline & $\bmod \mathrm{cthl}$ & 0 & & 1 & & 0 & 0 & 11 & 0 & 0 & 0 & 0 & 12 \\
\hline & $n$ & 1 & & 1 & & 0 & 0 & 0 & 0 & 0 & 0 & 6 & 8 \\
\hline & mils ehl & 2 & & 2 & & 0 & 11 & 0 & 0 & 0 & 0 & 0 & 15 \\
\hline & mildHSNHL & 0 & & 0 & & 0 & 0 & 0 & 2 & 0 & 0 & 0 & 2 \\
\hline & severe hf SNHL & 0 & & 0 & & 1 & 0 & 0 & 0 & 0 & 0 & 0 & 1 \\
\hline & mild mfSNHLL & 0 & & 0 & & 0 & 0 & 0 & 0 & 2 & 2 & 0 & 4 \\
\hline & mod mfSNHL. & 0 & & 1 & & 0 & 0 & 0 & 0 & 0 & 0 & 0 & 1 \\
\hline \multirow[t]{3}{*}{ Total } & & 8 & & 17 & & 4 & 11 & 11 & 2 & 2 & 2 & 6 & 63 \\
\hline & \multicolumn{5}{|c|}{ Chi-Square Tests } & & & & & & & & \\
\hline & & Value & d & $\begin{array}{l}\text { Asp } \\
\text { (2. }\end{array}$ & & & & & & & & & \\
\hline Pears: & achisquare & $291.888^{2}$ & 64 & & .000 & & & & & & & & \\
\hline
\end{tabular}

\section{TABLE: 6}

Table 6 shows the relationship between the left ear audiogram findings between patients of renal failure undergoing hemodialysis.

PTAl1: hearing status of left ear at $1^{\text {st }}$ month

PTAl3: hearing status of left ear at 3rd month

The result is significant as $\mathrm{p}$ value is $<.05$

There has been a significant increase in hearing threshold after two month of hemodialysis. 


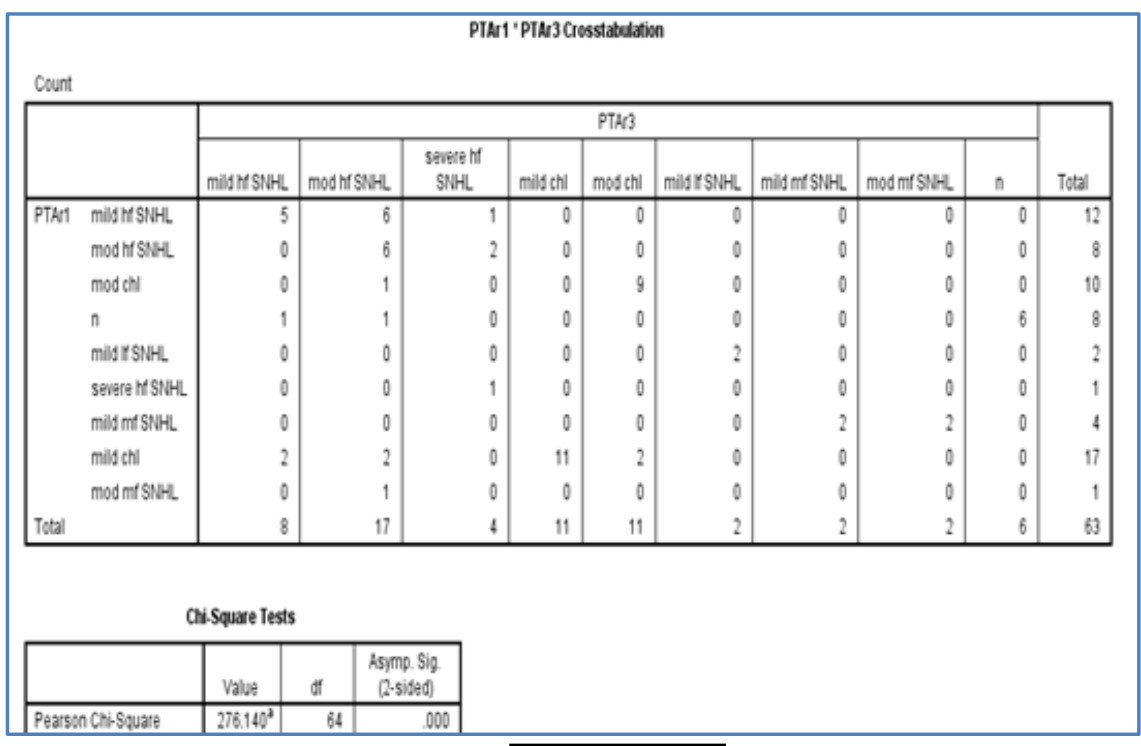

TABLE: 7

Table 7 shows the relationship between the right ear audiogram findings between patients of renal failure undergoing hemodialysis.

PTAr1: hearing status of right ear at $1^{\text {st }}$ month

PTAr3: hearing status of right ear at 3rd month

The result is significant as chi-square value is $<.05$

There has been a significant increase in hearing threshold after two month of hemodialysis.

DISCUSSION: Sensorineural hearing loss among patients with chronic kidney disease has been a common finding in studies investigating the effects of renal failure on auditory function. Despite differences in methodologies and indices of auditory function, existence of hearing loss has been a common threat. The higher incidence of hearing loss among patient with CKD has long been established and is constantly being verified by new studies.

A total of 63 patients of chronic renal failure were studied during the period of October 2011 to October 2012.The hearing loss in studied group of patients has been directly proportional to the duration of disease. $87.5 \%$ of patients had hearing loss with more than 18 month of disease compared to 33.3\% hearing loss with 6 month of disease. Risvi and Holmes ${ }^{7}$ reported a patient with progressive hearing loss parallel to progression of CRF, peritoneal dialysis and hemodialysis

According to our study the hearing loss was mostly on high frequency range around $77.14 \%$ of cases studied. Bergstrom et al. reported hearing loss in $40 \%$ of the CKD patients on hemodialysis. The cochlea in patients under the treatment with hemodialysis has been reported to be susceptible to various insults and the patients frequently exhibit some degree of sensorineural hearing loss, although the responsible etiological factor(s) still remain controversial ${ }^{8-9}$. In addition, the concurrent existence of these factors in each patient makes conclusions difficult on the significance of each. However, our study has shown significant depression in hearing threshold after 3 sessions of hemodialysis. Also, the presence of correlation between the post-treatment pure tone threshold and 
duration of illness and serum creatinine levels which was not found with the dosage of diuretics and blood pressure is similar to the report of Gatland et al ${ }^{8}$ and Hutter et al ${ }^{9}$. Gatland et al 8 reported decrease in threshold in 22/31 ears after dialysis but found no correlation with weight changes.

Gartland et al. 8 recorded pure tone thresholds on 31 patients before and after a session of hemodialysis. . Hutter et al ${ }^{9}$ reported acute onset hearing loss and neurologic symptoms within 24 hours after hemodialysis in 7 patients. They concluded that the injury was associated with exposure to aged cellulose acetate membranes of dialyzers, allowing acetate degradation product to enter the blood. Temporal bone study revealing severe loss of hair cell in the organ of corti after polybrene administration have further confirmed the ototoxic effect of polybrene and other macromolecular substances ${ }^{10-11}$. Henrich et al. ${ }^{12}$ found that $75 \%$ of the patients showed no deterioration of hearing during the 4-year time of follow-up. They concluded that hearing loss is common in renal failure, but it does not worsen with duration of treatment. Ozturan et al ${ }^{13}$ has concluded that there was no relationship between SHL and hemodialysis following a study of 15 subjects and 10 controls using PTA and DPOAE (Distortion Product Otoacoustic Emission) before and after hemodialysis, however, high frequency hearing loss was found but there was no difference between controls and subjects. In another related study. This conclusion was also supported by the study of Kusakari et a 14 . Serbetcioglu et a ${ }^{15}$ concluded that single session of hemodialysis had no significant adverse effect on hearing in a study of 19 patients with chronic renal failure undergoing hemodialysis. Visenscio and Gerber ${ }^{16}$ reported that pure tone thresholds did not change significantly after hemodialysis. They did observe individual threshold shifts which they attributed to temporary imbalance in the labyrinth caused by hemodialysis. They included $125 \mathrm{~Hz}$ in the audiograms and documented a low frequency hearing loss, which improved significantly on one-third of the patients after dialysis. In our study over 63 patients with three month follow up we found that there has been no improvement in hearing status with session of dialysis instead the hearing has either remained static or decreased. At the start of the study the hearing loss was $44.4 \%$ of the total 63 patient of which $64.28 \%$ were of mild degree, 32.14 were of moderate degree and 3.57\% were of severe degree hearing loss. At the end of follow up the hearing loss increased to $55.5 \%$ with $34.28 \%$ being of mild degree, 54.28 of moderate degree and 11.49 of severe degree hearing loss.

We suspect that the observed depression in hearing threshold after hemodialysis in this study could be due to a combination of changes in fluid and electrolyte composition of endolymph and possibly exposure to aged cellulose acetate membranes of dialyzers used, allowing acetate degradation product to enter the blood, however this may need further confirmation with temporal bone study.

Most previous studies did not find correlation between audiometric threshold and other variables such as blood pressure, use of ototoxic drugs, weight changes, hematocrit and metabolic bone disease. This is similar to our findings, although our result may have been influenced by the use of audiometer as the only audiologic modality used to assess the patients while some other investigators used DPOAEs and PTA 7,10,11,13. They reported that DPOAE seem to be more sensitive to incipient cochlear damage than behavior thresholds $7,10,11,13$. We had no facility for DPOAE in our center.

CONCLUSION: From this report it was concluded that there is increase in the high frequency hearing threshold of patients with CRF undergoing hemodialysis. This could be caused by changes induced by 
hemodialysis and the duration and severity of disease. However, there was no correlation with blood pressure and dosage of diuretics. The Hearing threshold must have increased with time due to vascular aging, but must not have reached pathological values. Another possibility is that the Hemodialysis might have increased the vascular aging process, and the third and the most probable explanation is that hearing loss in chronic renal failure patients is caused not only by preterm vascular aging, but also by some other factors which might have aggravated from Hemodialysis.

\section{REFERENCES:}

1. Quick CA, Fish A and Brown C. The relationship between the cochlea and the kidney. Laryngoscope. 1973, 83:1469-1482.

2. Bergstorm L, Jenkins P, Sando I, English GM. Hearing loss in renal disease: Clinical and pathological Studies. Ann Otol 1973; 82:555-76.

3. Adler D, Ritz E. Terminal renal failure and hearing loss. Arch Otorhinolaryngol 1982; 235:58790.

4. Quick CA, Fish A and Brown C. The relationship between the cochlea and the kidney Laryngoscope. 1973, 83:1469-1482.

5. Johnson DW, Mathog RH. Hearing function chronic renal failure. Annals of Otorhinolaryngology. 1976; 85:43-49.

6. Davison AM, Cameron JS, Grünfeld JP, Kerr DNS, Ritz E, Winearls CG. Oxford Textbook of Clinical Nephrology, 2nd edn. Oxford University Press, Oxford, UK, 1998.

7. Risvi SS, Holmes RA. Hearing loss from hemodialysis. Arch Otolaryngol 1980; 106: 751-756.

8. Gatland D, Tucker B, Chalstrey C, Keene M and Baker L. Hearing loss in chronic renal failurehearing threshold changes following haemodialysis. Journal of the Royal Society of Medicine. 1991; 84: 87-589.

9. Hutter JC, Kuehnert MJ, Wallis RR, Lucas AD, Sen S \& Jarvis WR. Acute onset decreased vision and hearing traced to hemodialysis treatment with aged dialysers Journal of the American Medical Association. 2000; 283:2128-2134

10. Kimura ET, Young PR, Barlow GH. A study of low and high molecular weights of hexadimethrine bromide - an antiheparin agent. Proceedings of Social and Experimental Biology. 1962; 111: 37 42.

11. Ransome J, Ballantyne JC, Shaldon S, Bosher SK and Hallpike CS. Perceptive deafness in subjects with renal failure treated with haemodialysis and polybrene. A clinicopathologic study. Journal of Laryngology and Otology. 1966; 80:651-677.

12. Henrich W, Thompson P, Bergstrom L, Lum GM. Effect of dialysis on hearing acuity. Nephron 1977; 18: 348-351.

13. Ozturan $\mathrm{O}$ and Lam $\mathrm{S}$. The effect of haemodialysis on hearing using pure - tone audiometry and distortion - product otoacoustic emissions. Otorhinolaryngology Journal of Otorhinolaryngology and Related Specialities.1998; 60: 306-313.

14. Kusakari J, Hara A, Takeyama M, Suzuki S \& Igari T. The hearing of the patients treated with haemodialysis: a long term follow-up study. Auris Nasus Larynx. 1992; 19:105-113.

15. Serbetcioglu MB, Erdogan S, Sifil A. Effects of a single session of hemodialysis on hearing abilities: Acta Otolaryngology. 2001; 121:836-838. 


\section{ORIGINAL ARTICLE}

16. Visencio LH, Gerber SE. Effects of hemodialysis on pure-tone thresholds and blood chemistry measures. J Speech Hear Res 1979; 22: 756-764.

\section{AUTHORS:}

1. Arjun Singh Doshad

2. Vaibhav Kuchhal

\section{PARTICULARS OF CONTRIBUTORS:}

1. IIIrd Year Post Graduate, Department of ENT, Sushila Tiwari Government Medical College, Haldwani, Uttar Khand.

2. Associate Professor and HOD, Department of ENT, Sushila Tiwari Government Medical College, Haldwani, Uttar Khand.

\section{NAME ADDRESS EMAIL ID OF THE CORRESPONDING AUTHOR:}

Dr. Arjun Singh Doshad, S-39, S.R. Hostet, Government Medical College,

Haldwani. Uttar Khand.

E-mail: arjun.pahari@rediffmail.com

Date of Submission: 02/01/2014.

Date of Peer Review: 03/01/2014.

Date of Acceptance: 17/01/2014.

Date of Publishing: 25/01/2014. 